\section{Abstract}

\title{
Assessment of the structural factors controlling the enzymatic saccharification of rice straw cellulose
}

\author{
Dong-June Seo*, Akiyoshi Sakoda \\ Institute of Industrial Science, The University of Tokyo \\ 4-6-1 Komaba, Meguro-ku, Tokyo 153-8505, Japan
}

In this study, the structural factors controlling the enzymatic saccharification of rice straw

cellulose were examined by preparing structure-modified rice straw samples such as dewaxed,

alkali-treated, oxidized, and swollen rice straw. It was found that the initial enzymatic

saccharification rate of the various structure-modified samples was largely controlled by the

initial cellulose surface area of the cellulose unit. Although the presence of lignin limited the

cellulose surface area, there was no strong relationship between the lignin content and the

initial reaction. On the other hand, the long-term enzymatic saccharification of rice straw

cellulose highly depended on the lignin removal rate (lignin content). It was also found that

silica is not a crucial factor in controlling the enzymatic saccharification.

\section{Keywords: Rice straw, Pretreatment, Cellulase, Saccharification}

${ }^{*}$ Corresponding author. Tel. (fax): +81-3-5452-6348;

E-mail addresses: bassdj80@iis.u-tokyo.ac.jp (D.-J. Seo), sakoda@iis.u-tokyo.ac.jp (A.

Sakoda). 
1

2 The securement of sustainable feedstock is one of the most important factors affecting the

3 feasibility of biorefinery. For this reason, lignocelluloses have attracted great attention as

4 sustainable feedstock for biorefinery. Lignocelluloses can be classified into the following

5 four groups [1]: 1) forest products/residues (e.g., eucalyptus, pine, and poplar), 2) agricultural

6 residues (e.g., corn stover, wheat straw, sugarcane bagasse, and rice straw), 3) agricultural

7 processing by-products (e.g., corn fiber, rice hull, and barley hull), and 4) dedicated energy

8 crops (e.g., hybrid poplar, switchgrass, and willow). Since the factors affecting availability of

9 the above lignocelluloses, including the land use for their cultivation, are geologically and

10 seasonally diverse, a strategy for biorefinery from these sources cannot be generalized. This

11 is the reason why many countries have been evaluating the potential of indigenous biomass

12 for biorefinery.

13 For many Asian countries including Japan, among the agricultural residues, rice straw

14 accounts for the major portion of the available biomass [2]. According to statistics supplied

15 by the Japanese government, the annual generation of rice straw in 2005 reached about $9 \mathrm{Mt}$;

16 however, most of this product is plowed down, with a little effective utilization (i.e., animal

17 feed and composting) that accounts for only about $20 \%$ of the total production. Considering

18 this situation, the utilization of rice straw as feedstock of biorefinery is quite meaningful in

19 those Asian countries in which the land use for energy crop cultivation is highly limited in 
1 terms of establishing an agricultural society for carbon circulation. From this viewpoint, the

2 feasibility of sugar-based biorefinery (e.g., ethanol production) using rice straw has been

3 widely discussed $[2,3]$. However, basic studies on the pretreatment and enzymatic

4 saccharification of rice straw, taking into account its intrinsic structural features, have not

5 been fully carried out, even though it is very important to optimize the sugar-based

6 biorefinery using rice straw.

7 In contrast to wooden stem, the stem of the rice straw monocots lacks a cambium, but it

8 has numerous vascular bundles in different layers consisting of a waxy cuticle, silicated

9 epidermis, cortex (collenchyma), a thick lignified layer (sclerenchyma), and ground tissue

10 (parenchyma), as shown in Fig. 1 [4].

11 Figure 1 here

12 Compared to woody biomass and other monocots, one of the intrinsic features of rice

13 straw is its silica-enriched body, which is known to be the main physical barrier to material

14 transportation along with the lignin that reduces the susceptibility to enzymatic degradation

15 [5]. Jin and Chen [4] reported that the proportion of lignin and the silica content in different

16 parts of rice straw (e.g., the leaf blade, node, and internode) showed a negative correlation

17 with the hydrolysis performance of cellulose.

18 Nonetheless, the enzymatic saccharification cannot be fully explained based on the

19 proportion of lignin to silica, because rice straw has a three-dimensional structure consisting 
1 of various layers. Moreover the negative effects of lignin and silica on the digestibility of rice

2 straw as an animal feed have been elucidated extensively for the last several decades [6], but

3 the structural factors governing the enzymatic saccharification of rice straw cellulose are still

4 not clear. Therefore, in this report, the structural factors controlling the enzymatic

5 saccharification of cellulose in rice straw have been studied taking into consideration the

6 intrinsic structure of rice straw. Based on the results, an effective pretreatment strategy for

7 rice straw was also discussed.

8

9 2. Material and Methods

10 2.1. Preparation of structure-modified rice straw samples

11 Straw of Japanese rice (Akitakomachi) harvested at maturity on October 2011 from a

12 single paddy field in Shinano $\left(36^{\circ} 48^{\prime} \mathrm{N}, 138^{\circ} 12^{\prime} \mathrm{E}\right.$, Nagano prefecture, Japan) was kindly

13 supplied by the rural rice farmer. Air-dried rice straw was coarsely cut to less than $30 \mathrm{~mm}$ by

14 cutting machine and stored in a dry space until further use. Rice straw was crushed to $(3 \pm 2)$

$15 \mathrm{~mm} \times(10 \pm 5) \mathrm{mm}$ pieces by using a manual roll crusher and air-dried to reduce the water

16 content (below $10 \%$, weight fraction). The crushed raw rice straw is termed RAW. The

17 authors intended to modify the rice straw structure in a stepwise approach to estimate more

18 clearly how each modification step (e.g. removal of wax and silica-enriched layers)

19 contributes to changes in the accessible cellulose surface area, since various components of 
1 rice straw affect exposure of the cellulose surface together. First, ethanol Soxhlet extraction

2 was carried out for $24 \mathrm{~h}$ to remove the wax from the cuticles of rice straw. The dewaxed

3 sample is hereafter termed DW. DW was treated to control silica-enriched layer (i.e.

4 epidermis) by immersion in a $940 \mathrm{~mol} \mathrm{~m}^{-3} \mathrm{Na}_{2} \mathrm{CO}_{3}$ (soda ash) solution under the following

5 conditions: liquid-to-solid ratio (L/S) of $20\left(\mathrm{dm}^{3} \mathrm{~kg}^{-1}\right)$, temperature of $62{ }^{\circ} \mathrm{C}$, and reaction

6 times of 20, 40, 90, and $180 \mathrm{~min}$. For the modification of densely lignified layer, DW was

7 treated by immersion in the oxidizing agent $\left(25 \% \mathrm{CH}_{3} \mathrm{COOH}+15 \%\right.$ of $30 \% \mathrm{H}_{2} \mathrm{O}_{2}+2.5 \%$

$8 \mathrm{H}_{2} \mathrm{SO}_{4}+57.5 \%$ distilled water, on a volume basis) described elsewhere [7] under the

9 following conditions: liquid-to-solid ratio (L/S) of $30\left(\mathrm{dm}^{3} \mathrm{~kg}^{-1}\right)$, temperature of $80^{\circ} \mathrm{C}$, and

10 reaction times of 20, 40, 90, and $180 \mathrm{~min}$. Alkali-treated and oxidized samples are referred to

11 as AL and OX, respectively. Swollen rice straw (referred to as SW hereafter) was also

12 prepared by wet ball milling of the alkali-treated sample for $180 \mathrm{~min}$ (AL180) at $0.4 \mathrm{~m} \mathrm{~s}^{-1}$ for

$133 \mathrm{~h}$ in a 0.5 -L milling pot (PM001, As one, Japan).

\subsection{Structural assessment of the model samples}

16 The compositional analysis was performed according to the method suggested by the

17 National Renewable Energy Laboratory (NREL, Denver, CO, US) [8, 9, 10]. For scanning

18 electron microscopy (SEM), the samples were air-dried and spread uniformly on the sample 
1 mounter and then were coated with Au before the observation using a field emission SEM

2 (FE-SEM) instrument (S-4500, Hitachi).

$3 \quad$ As an indirect structural analysis, cellulase (Celluclast $^{\circledR}$ 1.5L; CAS \#: 9012-54-8; Sigma

4 Aldrich Co.; protein concentration: $51.43 \pm 1 \mathrm{~g} \mathrm{dm}^{-3}$ ) adsorption (equilibrium and rate) and

5 astra blue (Santa Cruz biotechnology, Inc.) adsorption (equilibrium) were carried out. Since

6 the catalytic activity of cellulase can be maintained across a wide range of temperatures, the

7 amount of sample used as an adsorbent can be altered by the hydrolysis occurring during the

8 cellulase adsorption. Therefore, cellulase adsorption experiments were performed at $0-4{ }^{\circ} \mathrm{C}$

9 to maintain the catalytic activity of cellulase at a negligible level [7]. The protein

10 concentration was measured using the Bradford protein assay kit according to the instructions

11 provided by Thermo Scientific. Besides, since the adsorption of astra blue is very sensitive to

12 the adsorption conditions (e.g., $\mathrm{pH}$ and concentration of the adsorbate in the solution), the

13 adsorption conditions of astra blue were controlled to obtain monolayer adsorption using 25

$14 \mathrm{~mol} \mathrm{~m}^{-3} \mathrm{Na}_{2} \mathrm{~B}_{4} \mathrm{O}_{7} / \mathrm{HCl}$ buffer solution as described in Peterlin et al. [11]. The experimental

15 conditions for cellulase and astra blue adsorption are listed in Table 1.

16 Table 1 here

17 The Langmuir adsorption equilibrium and rate data were interpreted using the following

18 equations:

$$
\text { Adsorption isotherm } q=\frac{q_{s} K C_{e}}{1+K C_{e}}
$$


2 where $q, q_{s}, K, C_{e}, C$, and $k_{a d}$ are the amount of adsorbate adsorbed onto the unit sample ( $\mathrm{g} \mathrm{g}^{-}$

$\left.3^{1}\right)$, the monolayer saturation amounts of adsorbed adsorbate onto the unit sample $\left(\mathrm{g} \mathrm{g}^{-1}\right)$, the

4 Langmuir equilibrium constant $\left(\mathrm{dm}^{3} \mathrm{~g}^{-1}\right)$, the equilibrium concentration of adsorbate in

5 solution $\left(\mathrm{g} \mathrm{dm}^{-3}\right)$, the concentration of adsorbate in solution $\left(\mathrm{g} \mathrm{dm}^{-3}\right)$, and the adsorption rate

6 constant $\left(\mathrm{s}^{-1}\right)$, respectively.

\section{$8 \quad$ 2.3. Enzymatic saccharification}

9 The enzymatic saccharification of model samples was performed to examine the effect of

10 the structural properties on the process. During saccharification, the hydrolysate was sampled

11 and the concentrations of the reducing sugars (cellobiose and glucose) were monitored. The

12 cellulose conversion ratio was calculated as below.

$$
\text { Cellulose conversion ratio }(-)=
$$$$
\frac{0.9 \times \text { Glucose in solution }\left(\mathrm{g} \mathrm{dm}^{-3}\right)+0.95 \times \text { cellobiose in solution }\left(\mathrm{g} \mathrm{dm}^{-3}\right)}{\text { Initial cellulose in solution }\left(\mathrm{g} \mathrm{dm}^{-3}\right)}
$$

15 follows:

$\triangleright \quad$ column/temperature: Shodex sugar SP0810/80 ${ }^{\circ} \mathrm{C}$;

$17 \quad \triangleright \quad$ eluent: deionized water;

$\triangleright \quad$ flow rate: $1 \mathrm{~cm}^{3} \mathrm{~min}^{-1}$; 
$1 \quad \triangleright \quad$ detector: RI (refractive index).

2 The conditions of the enzymatic saccharification of the samples are also listed in Table 1.

\section{$4 \quad 3$. Results and discussion}

\section{3.1. Composition, surface morphology, and accessibility of the model samples}

6 Fig. 2a and Table 2 show the compositional changes in rice straw following the different

7 treatments. During the 3-h alkali treatment, $87.08 \%$ of ash and $41.88 \%$ of lignin were

8 removed but the hemicellulose and cellulose levels remained were almost unchanged. During

9 the 3-h oxidative treatment, $93.64 \%$ of lignin and $76.86 \%$ of hemicellulose were removed;

10 however, the ash (mainly silica) and cellulose contents were slightly decreased. Therefore, it

11 can be considered that the alkali treatment and oxidative treatment mainly affected the silica-

12 lignin matrix and lignin-hemicellulose matrix, respectively.

$13 \quad$ Figure 2 and Table 2 here

14 The SEM images of some representative samples are shown in Fig. 2b. The waxy silicated epidermis of RAW can be observed in Panel 2b-1. Although the ethanol extractives (wax)

16 accounting for about $15 \%$ of RAW were removed, the surface morphology of DW was not

17 very different from that of RAW. In contrast to the silica skeleton (2b-3) of RAW, the

18 structure of silica seemed to be changed during the alkali treatment (2b-4). Some silica

19 remained on the surface, appearing as a white ball. After the 3-h oxidative treatment, rice 
1 straw was bleached (whitened) and its cellulose surface was exposed (2b-5). However, the

2 silica body was still retained on the surface. The inner surface of the fibrils of the swollen rice

3 straw (2b-6) was exposed.

$4 \quad$ Based on the above results and previous references, it can be inferred how the structure of

5 rice straw was modified by each treatment. For DW, the RAW sample structure remained yet

6 the waxy cuticle layer was removed. During alkali treatment, the silica-lignin matrix was

7 removed preferentially. This is because the silica in the epidermis is not stand-alone but is

8 complexed with, mainly, lignin [12]. During the oxidative treatment, lignin and hemicellulose

9 were removed from across the various layers, yet the silica remained. Although silica-lignin

10 and lignin-hemicellulose were removed during the alkali and oxidative treatments

11 respectively, the frame of the cell wall was retained. However, the cell wall collapsed during

12 the wet ball milling (SW), exposing the inner fibril surface.

13 One of the structural properties of the model samples, the "accessibility to cellulase," can

14 be also deduced from the cellulase adsorption rate $[13,14]$. In particular, it is described as

15 initial accessibility, because the accessibility is altered by the cellulase action known as

16 amorphogenesis [15]. The cellulase adsorption parameters are summarized in Table 3.

17 As shown in Fig. $3 \mathrm{~b}$ and Table 3, the cellulase adsorption rate cannot be increased merely

18 by the removal of the silicated and lignified layers (i.e., exposure of the outer surface of rice

19 straw fibrils). On the other hand, the exposure of the inner surfaces of rice straw fibrils (SW) 
1 significantly increased the initial accessibility to cellulase. Oxidative treatment largely

2 increased the monolayer saturation amounts of the adsorbed cellulase for the model samples

$3\left(q_{s}\right)$; however, $q_{s}$ of the alkali-treated samples (AL40 and AL180) was not very different from

4 that of RAW and DW.

$5 \quad$ Table 3 and Figure 3 here

6 Since cellulase is supposed to adsorb also on non-cellulosic components (e.g., lignin, silica,

7 and hemicellulose) non-specifically [16], we cannot say that the amount of cellulase adsorbed

8 accurately reflects the surface reactivity (i.e., cellulose surface area) of the substrate to

9 cellulase. Therefore, the cellulose surface area of the model samples was examined by astra

10 blue adsorption and the details are explained in the following section.

12 3.2. The structural factor of rice straw determining the initial cellulase reaction rate

\subsubsection{The modification of the previous cellulose conversion model}

14 Although the structural properties of the model samples were provided as mentioned

15 above, it is still very difficult to quantitatively predict the factors governing the enzymatic

saccharification rate by using those fragmentary pieces of information. Moreover, in contrast

17 to the cellulosic substrates, the non-productive and irreversible adsorption of cellulase onto

18 non-cellulosic components should be monitored to examine the cellulase reaction with

19 lignocelluloses [17]. Unfortunately, it is extremely difficult to monitor those phenomena 
1 quantitatively. In this study, the structural factor of rice straw controlling the cellulase

2 reaction was examined by using the cellulose conversion model with modifications [7].

3 In the original work, a simple cellulose conversion model considers the cellulase-derived

4 (cellulase overcrowding and product inhibition) and substrate-derived (cellulose surface area)

5 factors controlling the reaction rate of cellulosic substrates [7]. In the previous model, the

6 substrates were assumed to be cylindrical cellulose fibrils, and the concept of "initial radius

7 of cellulose fibrils $\left(R_{0}\right)$ " was adopted to describe the initial surface area of the cylindrical

8 cellulose fibrils (as a reaction rate-controlling factor) as shown below.

9 cellulose fibrils $(\mathrm{kg})$, and total initial weight of cellulose fibrils $(\mathrm{kg})$, respectively. This basic

18 form corresponds to the specific activity of cellulase proposed by Igarashi et al. [18]. 

overcrowding and inhibition of products is expressed as

$$
\frac{d \alpha}{d t}=\frac{k_{1}}{R_{0}{ }^{2}}\left(\frac{Q}{s_{0}}\right)\left[\exp \left(-k_{2} \frac{1}{q_{m}} \frac{\alpha}{1-\alpha}\right)+k_{3}\right],(6)
$$

4 where $q_{m}$ is the monolayer saturation amount of the adsorbed cellulase onto the unit weight of

5 cellulose fibrils, and $k_{2}$ and $k_{3}$ are dimensionless reaction rate constants. The derivation and

6 development of Eq. (5) and (6) are omitted because they are described in detail in Seo et al.

$7 \quad[7]$.

8 Here, the authors considered that the specific surface area (SSA) of cellulose $\left(\mathrm{m}^{2} \mathrm{~kg}^{-1}\right)$

9 shown in Eq. (7) is equivalent to $A_{c}$ [Eq. (4)], since it is almost impossible to measure the

10 surface area of cellulose fibrils correctly.

$$
S S A=\frac{N_{A} a_{m} q_{m}}{M},(7)
$$

12 where $N_{A}, a_{m}$ and $M$ are the Avogadro's number $\left(\mathrm{mol}^{-1}\right)$, the occupied surface area of one

13 molecule of the adsorbate $\left(\mathrm{m}^{2}\right)$, and the molecular weight of the adsorbate $\left(\mathrm{kg} \mathrm{mol}^{-1}\right)$,

14 respectively. Therefore, $q_{\mathrm{m}}$ can be expressed as a function of the initial radius of cellulose

15 fibrils as reported below.

$$
\frac{1}{q_{m}}=R_{0}\left(\frac{\rho_{c}}{2}\right)\left(\frac{N_{A} a_{m}}{M}\right)
$$

$$
\frac{d \alpha}{d t}=\frac{k_{1}}{R_{0}{ }^{2}}\left(\frac{Q}{S_{0}}\right)\left[\exp \left(-k_{2}^{\prime} R_{0} \frac{\alpha}{1-\alpha}\right)+k_{3}\right],(9)
$$


1 where $k_{2}{ }^{\prime}$ is the revised reaction rate constant $\left(\mathrm{m}^{-1}\right)$. It can be noted that the increase of the

2 cellulose surface area (i.e., decrease in $R_{0}$ ) contributes not only to increasing the reaction rate

3 but also to relieving the reaction retardation.

4 Since the previous model was constructed and validated with cellulosic substrates, the

5 cellulase adsorption isotherm was used to examine the cellulose surface area. However,

6 cellulase adsorption cannot be used to examine the cellulose surface area of rice straw

7 samples as mentioned in the beginning of section 3.2. Therefore, the authors adopted the astra

8 blue adsorption technique. Astra blue is a well-known dye for the selective staining of

9 cellulose due to its strong affinity for cellulose molecules [19, 20].

10 Furthermore, since the total amount of cellulase adsorbed onto the cellulose fibrils $(Q)$

11 cannot be specified, the total amount of cellulase loaded $\left(C_{L}, \mathrm{~kg}\right)$ was used instead of $Q$ in the

12 revised cellulose conversion model. The revised equation is shown as Eq. (10).

$$
\frac{d \alpha}{d t}=\frac{k_{1}}{R_{0}^{2}}\left(\frac{C_{L}}{S_{0}}\right)\left[\exp \left(-k_{2}^{\prime} R_{0} \frac{\alpha}{1-\alpha}\right)+k_{3}\right]
$$

\subsubsection{Model calculation and validation}

16 Fig. 4a shows the astra blue adsorption isotherms of the model samples. The adsorption

17 parameters are listed in Table 3.

$18 \quad$ Figure 4 here 
2 blue onto the unit sample $\left(13.3 \mathrm{~g} \mathrm{~kg}^{-1}\right)$ was very similar to that of the bleached pulps $(13.8-$

$3 \quad 14.6 \mathrm{~g} \mathrm{~kg}^{-1}$ ) reported by Peterlin et al. [20]. Therefore, the SSA (i.e., cellulose surface area) of

4 the unit samples was calculated using Eq. (7) by using $q_{s}$ instead of $q_{m} . a_{m}$ and $M$ of the astra

5 blue were $5 \mathrm{~nm}^{2}$ and $1.06875 \mathrm{~kg} \mathrm{~mol}^{-1}$, respectively. The specific cellulose surface area

6 according to the removal rate of non-cellulosic materials is shown in Fig. 4b.

7 As shown in Fig. 4b-1, the cellulose surface area of the unit sample did not increase much

8 by removing the waxy layer. On the contrary, the cellulose surface area of the cellulose unit

9 (Fig. 4b-3) decreased due to the increase in the DW cellulosic fraction (Fig. 4b-2). The

10 cellulose surface area increased largely at around 40-60\% of removal rate. However, the

11 cellulose surface area of the unit sample was not increased over $45 \mathrm{~m}^{2} \mathrm{~g}^{-1}$ sample, although

12 nearly $80 \%$ of the non-cellulosic materials were removed. On the other hand, a larger value

13 was observed for SW compared to that of the other samples. As discussed in Section 3.1, this

14 is because the inner cellulose surface cannot be exposed merely by removing the outer layers.

15 Fig. 5a shows the initial cellulose conversion ratio (1 hr) of the model samples under

16 various cellulose-loading conditions. The experimental data were interpreted by using Eq.

17 (10).

$18 \quad$ Figure 5 here 
2 Eq. (10), are shown in Fig. 5a. The initial cellulose conversion ratio for the experimental

3 structure-modified samples was simulated by changing the initial radius ("relative $R_{0}$ " to

4 control's). All the calculated data are shown using the solid line. The calculations based on

5 the model were performed using the Scilab software. As shown in Fig. 5a, the simulated data

6 corresponded well to the experimental data for a wide range of cellulase loadings.

7 It is interesting to note that DW showed a lower initial cellulose conversion ratio than raw

8 rice straw, probably because DW has lower cellulose surface area of unit weight of cellulose

9 than RAW (Fig. 4b-3). In other words, the relatively larger initial radius $\left(R_{0}\right)$ of DW

10 compared to that of raw rice straw resulted in an initial poor cellulose conversion ratio.

11 The suggested model was validated by comparing the relative $R_{0}$ of the structure-modified

12 samples to $R_{0}$ of the control (RAW) by examining the astra blue adsorption and calculations

13 based on the model. As shown in Fig. 5b, the relative $R_{0}$ of all the samples but DW obtained

14 by model calculation was very close to the relative $R_{0}$ measured by astra blue adsorption.

15 Therefore, it can be concluded that measured suggested model quantitatively describes the

16 effect of the cellulose surface area on the initial enzymatic saccharification rate of rice straw

17 cellulose.

18 Similarly to a previous report showing that the initial enzymatic saccharification rate of

19 cellulosic substrates is largely controlled by the initial cellulose surface area of the cellulose 
1 unit [7], the initial enzymatic saccharification rate of rice straw cellulose is also mainly

2 affected by the initial cellulose surface area of the cellulose unit, although rice straw is a

3 much more heterogeneous substrate, based on the cellulase reaction.

$4 \quad$ Furthermore, the results shown in Fig. 4 clearly elucidated that the initial enzymatic

5 saccharification of rice straw cellulose was controlled not by the lignin or silica content itself

6 but by the initial cellulose surface area of the cellulose unit strongly related to the removal of

7 non-cellulosic materials, although previous work roughly estimated that the initial enzymatic

8 hydrolysis of rice straw would seem to be determined by the structure features, such as

9 number of accessible sites to cellulase [21].

11 3.3. The rice straw structural parameter determining the long-term cellulose conversion

12 Although the sensitivity of cellulose conversion of the cellulosic substrate to $R_{0}$ decreased

13 with the reaction time, the variation of the long-term reaction also could be described as a

14 function of $R_{0}[7]$. However, for the model rice straw samples, the variation of the long-term

15 enzymatic saccharification rate could not be successfully described by Eq. (10) using

16 estimated parameters for the initial reaction.

17 For lignocelluloses including rice straw, the uncertainties with respect to the cellulase

18 reaction might increase with the reaction time, because the probability that a biospecific

19 reaction between cellulose and cellulase could occur would decrease with the progression of 
1 cellulose conversion. In other words, irreversibly-/non-productively-bound cellulase to the

2 non-cellulosic materials might increase with the reaction time [17]. Therefore, a reliable

3 description of the available cellulase quantity considering its irreversible/non-productive

4 adsorption is necessary to enhance the accuracy of Eq. (10) for the long-term cellulose

5 conversion [17]. However, although this is an old, unresolved issue in this field, it is not an

6 objective of this study to address this.

7 Fig. 6a shows the variation in the cellulose conversion ratio during the $72-\mathrm{h}$ period for the

8 model samples.

$9 \quad$ Figure 6 here

10 Not only at the beginning of the reaction, but also during the reaction, the cellulose

11 conversion ratio of DW was lower than that of raw rice straw. Therefore, it can be inferred

12 that any treatment that does not contribute to increase the initial cellulose surface area of the

13 cellulose unit cannot be a pretreatment during the process of enzymatic saccharification of

14 rice straw cellulose. Although SW showed higher initial reaction rate than other samples due

15 to the higher initial cellulose surface area of the cellulose unit (Fig. 4 and 5), the variation of

16 the cellulose conversion ratio over time was quite similar to that of AL180, which shows a

17 same composition. The reason underlying this finding is unclear and hard to explain by

18 referring to the results obtained in this study. Nonetheless, it can be expected that a physical

19 treatment (e.g., ball milling) may expose not only the inner cellulose surface, but also more of 
1 the lignin surface covering the cellulose microfibrils. This can also be inferred from the

2 results shown in Fig. 4a (inner panel). Considering that creating a finer particle by crushing

3 could not increase the cellulose-containing surface area of raw rice straw, it is thought that

4 the physically increased surface area obtained by crushing may be a lignin-containing surface.

5 The impact of structural factors (i.e. silica, lignin and hemicellulose) on the long-term

6 cellulase reaction was estimated by multiple linear regression as follows:

$$
y=\beta_{0}+\beta_{1} x_{1}+\beta_{2} x_{2}+\beta_{3} x_{3},(11)
$$

$7 \quad$ where $y$ and $\beta_{i}(i=0-3)$ are the cellulose conversion ratio at $72 \mathrm{~h}$ as a response variable and

8 the regression coefficients, respectively. $x_{1}, x_{2}$ and $x_{3}$ are independent variables given by:

$$
x_{1}=\left(\frac{S i}{C_{L}}\right), x_{2}=\left(\frac{L}{C_{L}}\right) \text { and } x_{3}=\left(\frac{H}{C_{L}}\right)
$$

where $\mathrm{Si}, L, H$ and $C_{L}$ are the amounts of silica, lignin, hemicellulose and cellulase loaded

11 for enzymatic saccharification. The statistical analysis was performed using the Origin

12 program. The relationships between the fitted cellulose conversion ratio at $72 \mathrm{~h}(y)$ by

13 multiple linear regression and independent variables $\left(x_{1}, x_{2}\right.$ and $\left.x_{3}\right)$ are shown in Fig.6b. A

14 summary of the multiple linear regression is also listed in Table 4. Considering the $p$-values

15 and standardized coefficients, silica does not seem to be a crucial structural factor for

16 determining the long-term cellulase reaction, whereas lignin was estimated to have a high

17 impact. Yang et al., also pointed out that the ratio of delignification during pretreatment is a

18 crucial factor affecting enzymatic saccharification of rice straw cellulose [22]. 
Actually, the silica layer works as a barrier to protect the vascular system by limiting the

2 materials' access during the growth phase of the rice crop (see Fig. 1). However, it is

3 expected that the silica layer (micrometer-scale) cannot be a crucial factor in controlling the

4 materials' access once the rice straw is crushed because the effect of the directional property

5 of the silica layer on the limitation of materials' access is weakened, in contrast to that of

6 lignin directly covering the cellulose microfibrils on a nano-scale order. If silica combines

7 with cellulose fibrils in rice straw as the silica-carbohydrates complex found at the early stage

8 of secondary wall formation for some reed grasses [23], silica may hinder the cellulase

9 reaction. However, it is reported that silica mainly binds with phenol- or lignin-moieties but

10 not with carbohydrate in rice plant [12].

11 Hemicellulose located between lignin and cellulose fibrils is one of the barriers that limits

12 the accessibility of cellulase to cellulose fibrils [24, 25], but some recent studies have claimed

13 that hemicellulose has a positive effect on enzymatic saccharification of lignocelluloses [4,

$1426]$ probably because of the negative effect of hemicellulose on the crystallinity of cellulose

15 fibrils [26]. Although further specific discussion about this is not available in this study, at

16 least hemicellulose does not seem to have a strong negative effect on the long-term

17 saccharification of rice straw cellulose since the standardized coefficient of $x_{3}$ was estimated

18 to be a positive number. 
2 are controlled by the cellulose surface area of the cellulose unit and the lignin content,

3 respectively. As mentioned above, it is inferred that the highly sensitive behavior of cellulase

4 to cellulose surface area at the initial reaction stage could be possibly changed to be more

5 sensitive to lignin as the reaction time increased. Nevertheless, a topochemical approach is

6 needed to discuss which lignin (e.g. lignins in middle lamella, primary and secondary cell

7 wall for different vessels and parenchyma cell) is more crucial for enzymatic saccharification

8 of rice straw cellulose $[25,27]$.

\section{3.4. Effective pretreatment of rice straw}

11 Pretreatments of lignocelluloses enhance the accessibility of cellulose to cellulase, namely

12 the biospecific adsorption between cellulose and cellulase is increased by pretreatments.

13 Furthermore, pretreatments have the function of increasing the theoretical yield of the end-

14 products (e.g., glucose or ethanol) in the reaction system (e.g., saccharification or SSF;

15 simultaneous saccharification and fermentation). Considering that solid (substrate) loading

16 for the reaction is physically limited to certain levels to maintain proper mixing conditions, it

17 is considered that pretreatments contribute to obtaining a higher theoretical concentration of

18 the end-products in the reaction system by increasing the cellulose content of rice straw (i.e.,

19 removal of non-cellulosic materials). 
2 degree of removal of non-cellulosic materials, in particular, the first two are highly related to

3 the removal of lignin. Therefore, a superior pretreatment method of rice straw for the removal

4 of non-cellulosic materials (especially, lignin) and for the preservation of cellulose should be

5 adopted.

6 Actually, there are many pretreatment methods of lignocelluloses such as biological (e.g.,

7 white/brown-rot fungi), chemical (e.g., diluted acid, alkali, wet oxidation, organosolv, and

8 ionic liquid), physicochemical (e.g., ammonia fiber expansion, steam explosion, and $\mathrm{CO}_{2}$

9 explosion) and physical or mechanochemical (e.g., wet/dry milling, wet disk,

10 ultrasonification, and microwave irradiation) [28]. Nonetheless, alkali-based pretreatment is

11 considered to be the most effective on rice straw, because the lignin content of rice straw is

12 lower than that of woody biomass and the "pealing effect" of alkali can contribute to remove

13 multiple layers of rice straw [29]. In addition, rice straw is rich in $p$-hydroxyphenyl, which

14 solubilizes straw lignin in alkali solutions [30]. As shown in this study, silica and lignin can

15 be simultaneously removed by using alkali. According to the pretreatment conditions (e.g.,

16 temperature, pressure, and alkali loading), hemicellulose can also be removed. Moreover,

17 alkali-based pretreatment is superior to other pretreatments in preserving cellulose. This also

18 agrees with the opinion of previous studies reporting that alkali-based pretreatments (e.g.,

19 ammonia, lime, and $\mathrm{NaOH}$ ) are more effective on herbaceous biomass and agricultural 
1 residues than on woody biomass [29, 31, 32]. However, many factors such as process

2 capacity, targeted end-product, and following treatments should be considered

3 comprehensively in order to choose the appropriate pretreatment method, because each

4 method has its advantages and disadvantages.

5

6 4. Conclusions

7 In this study, the structural factors controlling the enzymatic saccharification of rice straw

8 cellulose were examined by preparing structure-modified rice straw samples and the main

9 findings are as follows:

(i) The initial enzymatic saccharification of rice straw cellulose was not controlled by the

11 silica or lignin itself but by the initial cellulose surface area of the cellulose unit strongly

12 related to the removal of non-cellulosic materials (e.g. silica, lignin and hemicellulose).

(ii) The removal rate of lignin affected the long-term enzymatic saccharification of rice

14 straw cellulose significantly, but that of silica did not.

15 Although lignin removal is crucial to enhance the initial and long-term reaction by

16 exposure of the cellulose surface and reduction of the non-productively bound cellulase,

17 respectively, the removal of other non-cellulosic materials and the preservation of cellulose

18 during the pretreatment are also important, because high cellulose contents in feedstock are

19 preferable for obtaining abundant end-products. 
2 Acknowledgements

3 This work was in part supported by JST/JICA, SATREPS, "Sustainable Integration of Local

4 Agriculture and Biomass Industries."

5

6 References

7 [1] Drapcho CM, Nhuan NP, Walker TH. Biofuels engineering process technology. New

$8 \quad$ York NY: McGraw-Hill;2008.

9 [2] Binod P, Sindhu R, Singhania RR, Vikram S, Devi L, Nagalakshmi S, et al. Bioethanol

10 production from rice straw: an overview. Bioresour Technol 2010;101(13):4767-74.

11 [3] Matsumura Y, Minowa T, Yamamoto H. Amount, availability, and potential use of

12 rice straw (agricultural residue) biomass as an energy resource in Japan. Biomass

$13 \quad$ Bioenerg 2005;29(5):347-54.

14 [4] Jin S, Chen H. Structural properties and enzymatic hydrolysis of rice straw. Process

$15 \quad$ Biochem 2006;41(6):1261-4.

16 [5] Currie HA, Perry CC. Silica in plants: biological, biochemical and chemical studies.

$17 \quad$ Ann Bot 2007;100(7):1383-9. 
1 [6] Van Soest PJ. Rice straw, the role of silica and treatments to improve quality. Anim Feed Sci Technol 2006;130(3-4):137-71.

[7] Seo D-J, Fujita H, Sakoda A. Numerical analysis of the impact of structural changes in cellulosic substrates on enzymatic saccharification. Bioresour Technol 2012;118:32331.

[8] Sluiter A, Hames B, Ruiz R, Scarlata C, Sluiter J, Templeton D, et al. Determination of Structural Carbohydrates and Lignin in Biomass. Golden, Colorado: 2010, Jul, 17p, Report No. TP-510-42618

[9] Hames B, Ruiz R, Scarlata C, Sluiter A, Sluiter J, Templeton D. Preparation of Samples for Compositional Analysis. Golden, Colorado: 2008, Aug, 9p, Report No. TP-510-42620

[10] Sluiter A, Hames B, Ruiz R, Scarlata C, Sluiter J, Templeton D. Determination of Ash in Biomass. Golden,Colorado: 2005, Jul, 5p, Report No. TP-510-42622

[11] Peterlin S, Drnovšek T, Perdih A, Dolenc D. Surface characterization of stepwise oxidized spruce thermomechanical pulp samples by different analytical methods. Cellulose 2009;16(5):833-9. 
1 [12] Inanaga S, Okasaka A. Calcium and silicon binding compounds in cell walls of rice

2 shoots. Soil Sci Plant Nutr 1995;41(1):103-10.

3 [13] Zhang YP, Lynd LR. Toward an aggregated understanding of enzymatic hydrolysis of cellulose: noncomplexed cellulase systems. Biotechnol Bioeng 2004;88(7):797-824.

5 [14] Kumar R, Wyman CE. Physical and Chemical Features of Pretreated Biomass that Influence Macro-/Micro-Accessibility and Biological Processing. Aqueous Pretreat Plant Biomass Biol Chem Convers to Fuels Chem 2013:281-310.

[15] Arantes V, Saddler JN. Access to cellulose limits the efficiency of enzymatic hydrolysis: the role of amorphogenesis. Biotechnol Biofuels 2010;3:1-11.

[16] Palonen H, Tjerneld F, Zacchi G, Tenkanen M. Adsorption of Trichoderma isolated lignin. J Biotechnol 2004;107(1):65-72.

[17] Zheng Y, Pan Z, Zhang R, Jenkins BM. Kinetic modeling for enzymatic hydrolysis of pretreated creeping wild ryegrass. Biotechnol Bioeng 2009;102(6):1558-69. crystalline celluloses. Febs J 2006;273(13):2869-78. 
1 [19] Drnovšek T, Perdih A. Selective staining as a tool for wood fibre characterization. Dye

2

3 [20] Peterlin S, Drnovšek T, Perdih A, Dolenc D. Dyeing of papermaking fibers with dyes

4

5

6 [21] Hsu T-C, Guo G-L, Chen W-H, Hwang W-S. Effect of dilute acid pretreatment of rice

Pigment 2005;67(3):197-206.

of various structural types as a means for fiber surface characterization. Acta Chim Slov 2009;56(2):418-25. straw on structural properties and enzymatic hydrolysis. Bioresour Technol 2010;101(13):4907-13.

[22] Yang L, Cao J, Jin Y, Chang H, Jameel H, Phillips R, et al. Effects of sodium carbonate pretreatment on the chemical compositions and enzymatic saccharification of rice straw. Bioresour Technol 2012;124:283-91.

[23] Perry CC, Williams RJP, Fry SC. Cell wall biosynthesis during silicification of grass hairs. J Plant Physiol 1987;126(4-5):437-48.

[24] Zhang Y-HP. Reviving the carbohydrate economy via multi-product lignocellulose biorefineries. J Ind Microbiol Biotechnol 2008;35(5):367-75. 
1 [25] Siqueira G, Milagres AMF, Carvalho W, Koch G, Ferraz A. Topochemical distribution

2 of lignin and hydroxycinnamic acids in sugar-cane cell walls and its correlation with the enzymatic hydrolysis of polysaccharides. Biotechnol Biofuels 2011;4:7-16.

4 [26] Xu N, Zhang W, Ren S, Liu F, Zhao C, Liao H, et al. Hemicelluloses negatively affect lignocellulose crystallinity for high biomass digestibility under $\mathrm{NaOH}$ and $\mathrm{H}_{2} \mathrm{SO}_{4}$ pretreatments in Miscanthus. Biotechnol Biofuels 2012;5:58.

7

8

9

[27] Rehbein M, Koch G. Topochemical investigation of early stages of lignin modification within individual cell wall layers of Scots pine (Pinus sylvestris L.) sapwood infected by the brown-rot fungus Antrodia vaillantii (DC.: Fr.) Ryv. Int Biodeterior Biodegradation 2011;65(7):913-20.

[28] Alvira P, Tomás-Pejó E, Ballesteros M, Negro MJ. Pretreatment technologies for an efficient bioethanol production process based on enzymatic hydrolysis: a review. Bioresour Technol 2010;101:4851-61.

[29] Chen Y, Stevens MA, Zhu Y, Holmes J, Xu H. Understanding of alkaline pretreatment parameters for corn stover enzymatic saccharification. Biotechnol Biofuels 2013;6:110.

[30] Ghaffar SH, Fan M. Structural analysis for lignin characteristics in biomass straw. Biomass Bioenerg 2013;57:264-79. 
1 [31] Han L, Feng J, Zhang S, Ma Z, Wang Y, Zhang X. Alkali pretreated of wheat straw and its enzymatic hydrolysis. Brazilian J Microbiol 2012;43(1):53-61.

3 [32] Taherzadeh MJ, Karimi K. Pretreatment of lignocellulosic wastes to improve ethanol and biogas production: a review. Int J Mol Sci 2008;9(9):1621-51.

5 
List of Tables

Table 1 . The summary of the conditions of the adsorption and enzymatic saccharification experiments.

Table 2. The composition of model rice straw samples and loss of major components during the treatments.

Table 3. The adsorption parameters for model rice straw samples.

Table 4. The summary of the multiple linear regression. 
Table 1. The summary of the conditions of the adsorption and enzymatic saccharification experiments.

\begin{tabular}{|c|c|c|c|c|}
\hline & \multicolumn{2}{|c|}{ Cellulase adsorption } & \multirow{2}{*}{$\begin{array}{c}\text { Enzymatic } \\
\text { saccharification }\end{array}$} & Astra blue adsorption \\
\hline & Equilibrium & Rate & & Equilibrium \\
\hline Buffer (pH) & \multicolumn{3}{|c|}{$50 \mathrm{~mol} \mathrm{~m}^{-3}$ Acetic buffer (pH 4.8) } & $25 \mathrm{~mol} \mathrm{~m}^{-3} \mathrm{Na}_{2} \mathrm{~B}_{4} \mathrm{O}_{7} / \mathrm{HCl}(\mathrm{pH} 8)$ \\
\hline Temp. $\left({ }^{\circ} \mathrm{C}\right)$ & \multicolumn{2}{|c|}{$0-4^{\circ} \mathrm{C}$} & $50^{\circ} \mathrm{C}$ & Room \\
\hline Time (h) & 6 & $\begin{array}{c}1,2,4, \\
8, \text { and } 12\end{array}$ & $\begin{array}{c}1,3,6,12, \\
24,48, \text { and } 72\end{array}$ & 1.5 \\
\hline $\mathrm{L} / \mathrm{S}\left(\mathrm{dm}^{3} \mathrm{~kg}^{-1}\right)$ & \multicolumn{2}{|c|}{100} & 60 & $120-150$ \\
\hline \multirow{2}{*}{$\begin{array}{l}\text { Adsorbate } \\
\text { loading }\end{array}$} & $0.005-1.2$ & 0.13 & \multirow{2}{*}{$\begin{array}{c}0.014-0.136 \\
\text { ( } \mathrm{g} \mathrm{g}^{-1} \text { of cellulose) }\end{array}$} & \multirow{2}{*}{$\begin{array}{c}0.004-0.2 \\
\left(\mathrm{~g} \mathrm{~g}^{-1} \text { of sample) }\right.\end{array}$} \\
\hline & \multicolumn{2}{|c|}{ ( $\mathrm{g} \mathrm{g}^{-1}$ of sample) } & & \\
\hline $\begin{array}{c}\text { Measurement } \\
\text { method }\end{array}$ & \multicolumn{2}{|c|}{ Bradford protein assay } & HPLC & UV spectrometer (609 nm) \\
\hline
\end{tabular}


Table 2. The composition of model rice straw samples and loss of major components during the treatments

\begin{tabular}{|c|c|c|c|c|c|c|c|c|c|c|c|c|}
\hline & \multirow{2}{*}{$\begin{array}{c}\text { EtOH- } \\
\text { extractives }\end{array}$} & \multirow{2}{*}{$\begin{array}{l}\text { Water- } \\
\text { solubles }\end{array}$} & \multirow{2}{*}{$\begin{array}{c}\text { Ash } \\
\text { (silica) }\end{array}$} & \multirow{2}{*}{ Lignin } & \multirow{2}{*}{ Cellulose } & \multirow{2}{*}{$\begin{array}{l}\text { Hemi- } \\
\text { cellulose }\end{array}$} & \multirow{2}{*}{$\begin{array}{l}\text { Total } \\
\text { mass } \\
(\%)\end{array}$} & \multicolumn{5}{|c|}{ Mass loss (\%) } \\
\hline & & & & & & & & $\mathrm{Si}$ & $\mathrm{L}$ & $\mathrm{H}$ & $\mathrm{Si}+\mathrm{L}$ & $\mathrm{L}+\mathrm{H}$ \\
\hline RAW & 15.35 & 7.87 & 8.60 & 11.27 & 33.54 & 15.92 & 100 & - & - & - & - & - \\
\hline DW & - & 9.3 & 10.15 & 13.32 & 39.62 & 18.8 & 84.65 & - & - & - & - & - \\
\hline AL20 & - & - & 5.97 & 12.55 & 46.12 & 22.11 & 68.44 & 52.47 & 23.85 & 4.91 & 36.23 & 12.77 \\
\hline AL40 & - & - & 3.89 & 12.65 & 47.12 & 22.01 & 65.77 & 70.24 & 26.23 & 9.02 & 45.27 & 16.16 \\
\hline AL90 & - & - & 3.14 & 12.18 & 50.51 & 27.01 & 63.19 & 76.94 & 31.74 & na & 51.29 & 8.91 \\
\hline $\begin{array}{c}\text { AL180 } \\
\text { (SW) }\end{array}$ & - & - & 1.82 & 10.75 & 53.66 & 28.4 & 60.99 & 87.08 & 41.88 & na & 61.43 & 12.2 \\
\hline OX20 & - & - & 12.87 & 10.38 & 42.71 & 22.48 & 60.65 & 9.2 & 44.17 & 14.35 & 29.04 & 26.71 \\
\hline OX40 & - & - & 15.9 & 7.02 & 48.77 & 15.95 & 52.06 & 3.7 & 67.59 & 47.82 & 39.95 & 56.02 \\
\hline OX90 & - & - & 15.51 & 2.45 & 60.88 & 10.13 & 48.04 & 13.3 & 89.55 & 69.41 & 56.57 & 77.76 \\
\hline OX180 & - & - & 17.03 & 1.54 & 62.26 & 7.9 & 46.60 & 7.66 & 93.64 & 76.86 & 56.45 & 83.82 \\
\hline
\end{tabular}


Table 3. The adsorption parameters for model rice straw samples.

\begin{tabular}{c|c|c|c|c|c}
\hline \multirow{2}{*}{ Samples } & \multicolumn{3}{|c|}{ Cellulase adsorption } & \multicolumn{2}{c}{ Astra blue adsorption } \\
\cline { 2 - 6 } & $q_{s}$ & $K$ & $k_{a d}\left(\times 10^{-4}\right)$ & $q_{s}\left(\times 10^{-3}\right)$ & $K$ \\
\hline RAW & 0.104 & 0.308 & 1.416 & 6.109 & 10.128 \\
\hline DW & 0.115 & 0.261 & 1.661 & 6.689 & 10.128 \\
\hline AL40 & 0.126 & 0.294 & 1.884 & 11.221 & 5.000 \\
\hline AL180 & 0.173 & 0.215 & 1.757 & 13.360 & 4.700 \\
\hline OX20 & 0.373 & 0.145 & 1.970 & 9.212 & 8.000 \\
\hline OX180 & 0.500 & 0.105 & 2.907 & 15.779 & 4.664 \\
\hline SW & 0.495 & 0.184 & 502 & 21.912 & 7.963 \\
\hline
\end{tabular}


Table 4. The summary of the multiple linear regression.

\begin{tabular}{c|c|c|c|c|c|c}
\hline & coefficient $\left(\beta_{i}\right)$ & $\mathrm{SE}$ & $t$-value & $p$-value & $\mathrm{SC}$ & Statistics \\
\hline Intercept & 1.0470 & 0.1281 & 8.1740 & $5.32 \mathrm{E}-06$ & & \multirow{2}{*}{$\mathrm{N}=15$} \\
\cline { 1 - 5 }$x_{1}$ & -0.0047 & 0.0121 & -0.3873 & 0.7059 & -0.04977 & \multirow{2}{*}{ Adj. $\mathrm{R}^{2}=0.8584$} \\
\hline$x_{2}$ & -0.1375 & 0.0188 & -7.3075 & $1.53 \mathrm{E}-05$ & -1.08209 & \\
\hline$x_{3}$ & 0.0411 & 0.0162 & 2.5310 & 0.0279 & 0.382134 & \\
\hline
\end{tabular}

SE: standard error, SC: standardized coefficient 
List of Figures

Figure 1 (a) Schematic image of the structure of rice straw

Figure 2 (a) Compositional changes of rice straw according to the structure modification (b) SEM images of structure-modified rice straw samples (b-1: RAW; b-2: DW; b-3: Silica skeleton obtained by ashing the raw rice straw at $570{ }^{\circ} \mathrm{C}$; b-4: AL180; b-5: OX180; b-6: SW).

Figure 3 Adsorption isotherms (a) and adsorption rates (b) of cellulase.

Figure 4 Adsorption isotherms of astra blue for model samples (a) and different particle sizes of raw rice straw (a: inner). Changes in cellulose surface area of the unit sample (b-1), cellulose unit (b-3), and cellulose portion (b-2) according to the removal rate of non-cellulosic materials [EtOH-extracts (Wax), ash/silica (Si), lignin (L) and hemicellulose (H)].

Figure 5 Simulation of the initial cellulose conversion ratio of model samples (a) and comparison between the relative $\mathrm{R}_{0}$ of model samples obtained by astra blue adsorption and model calculation (b).

Figure 6 Variation of the cellulose conversion ratio of the model samples during $72 \mathrm{~h}$ (cellulase loading: $0.05 \mathrm{~g} \mathrm{~g}^{-1}$ of cellulose) (a) and relationships between the fitted cellulose conversion ratio at $72 \mathrm{~h}$ by multiple linear regression and independent variables (b). 


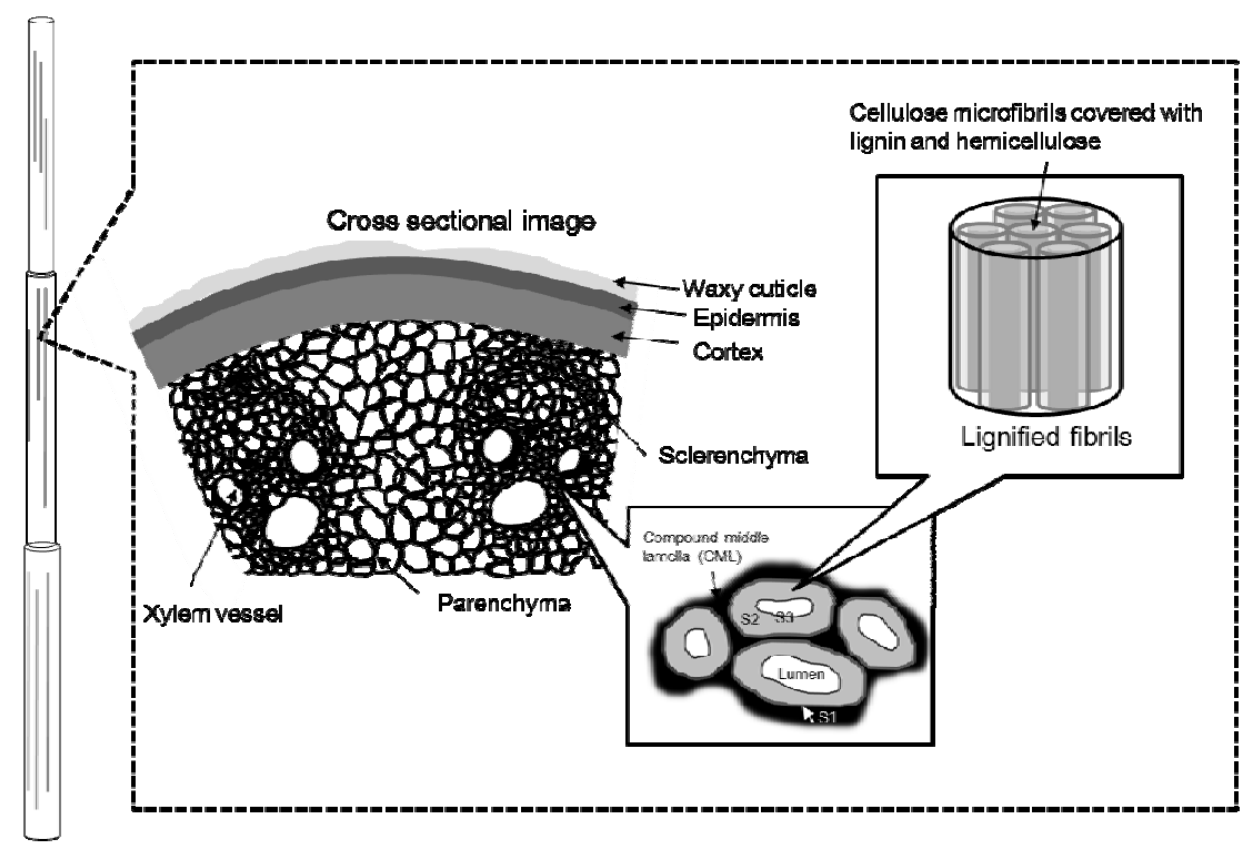

Hollow tubular structure of rice straw

Figure 1 


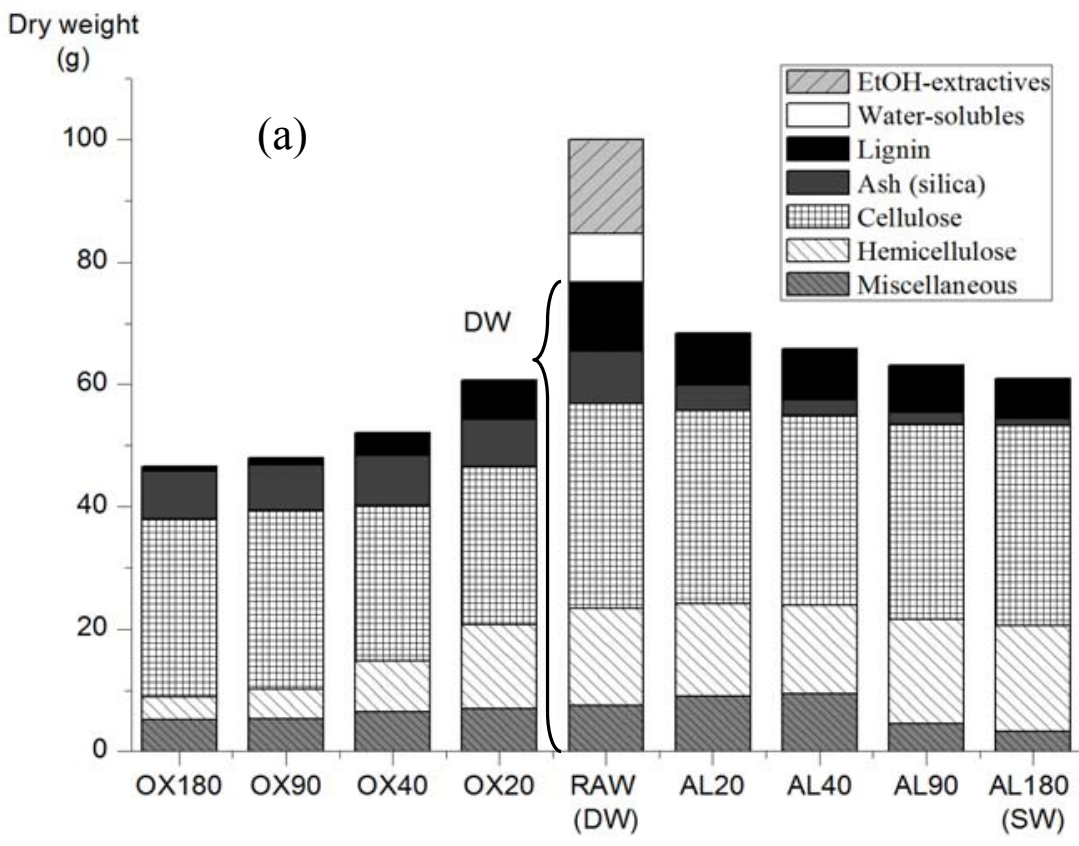

(b-1)

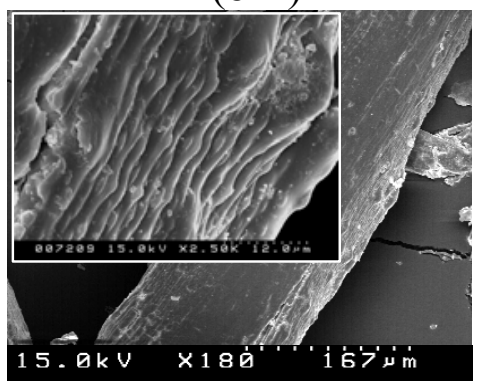

(b-3)

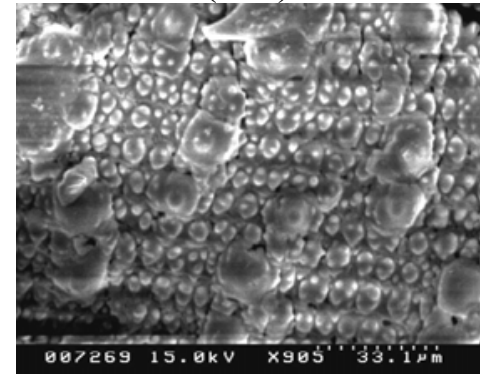

(b-5)

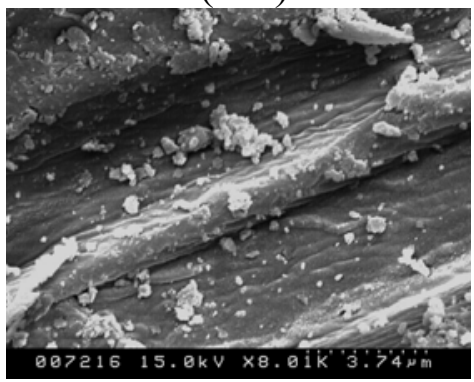

(b-2)

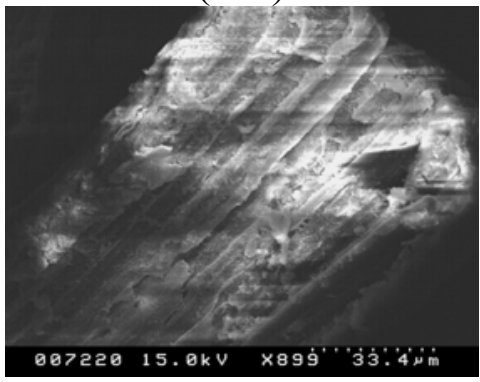

(b-4)

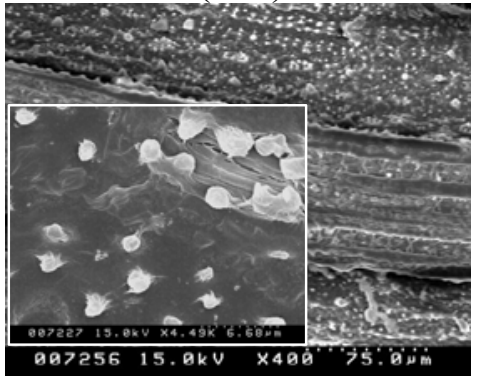

(b-6)

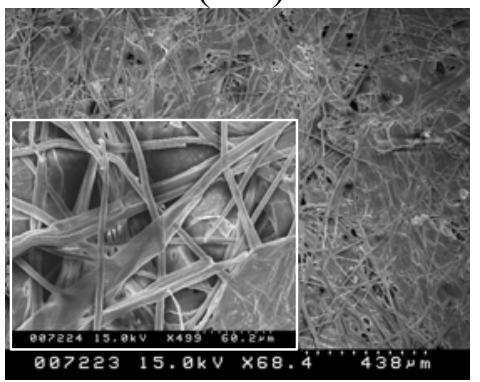

Figure 2 

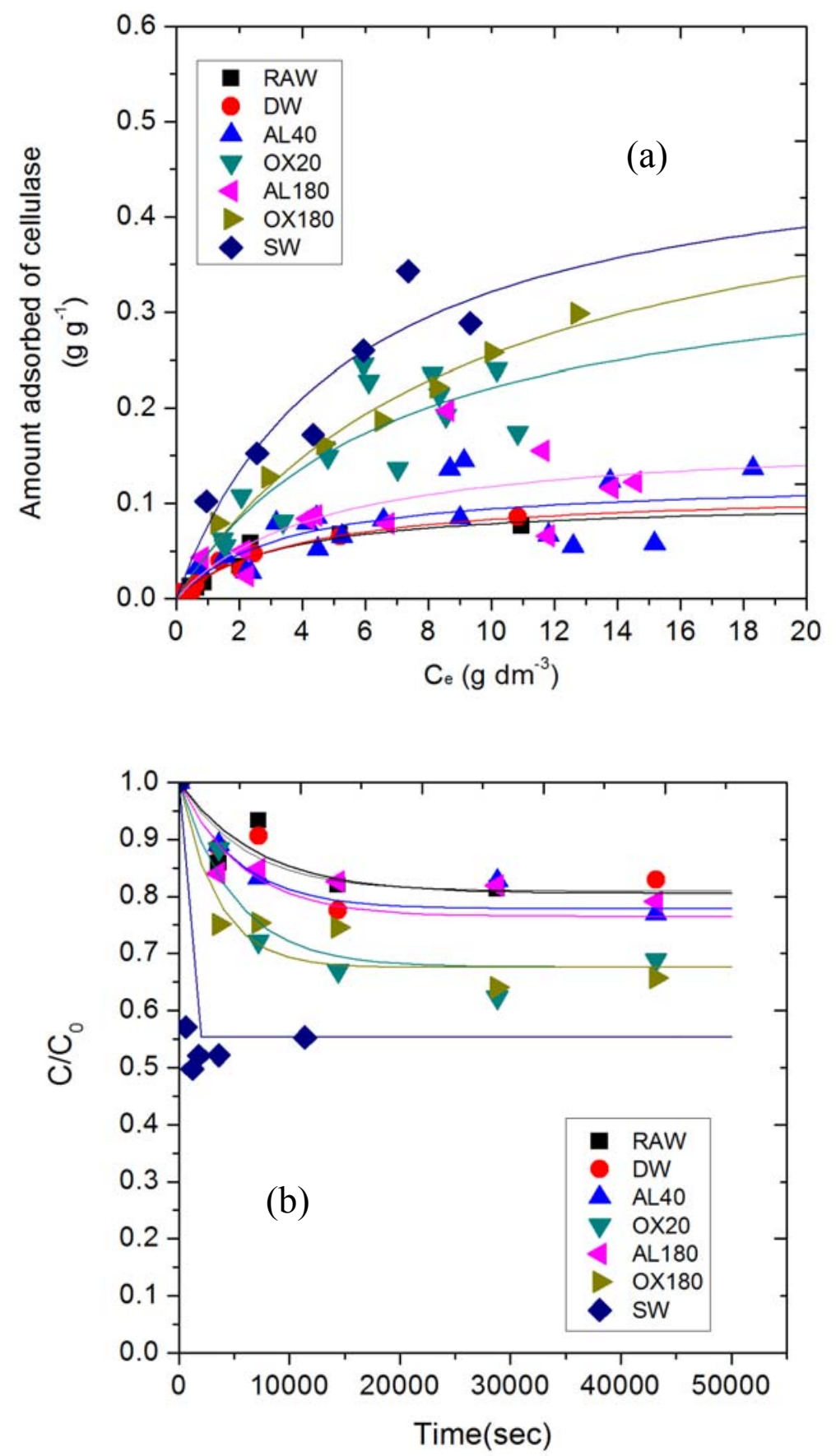

Figure 3 

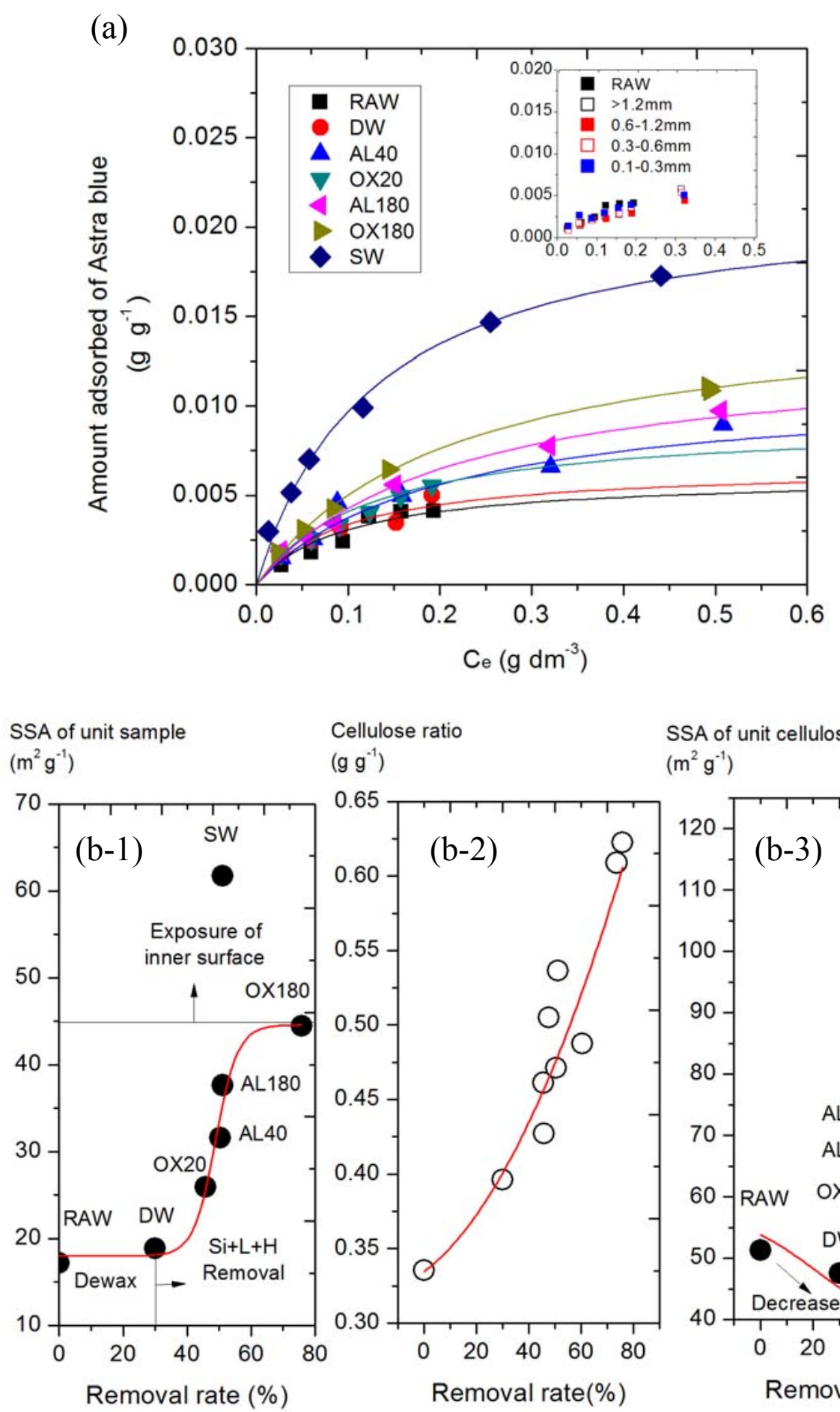

SSA of unit cellulose

$\left(\mathrm{m}^{2} \mathrm{~g}^{-1}\right)$

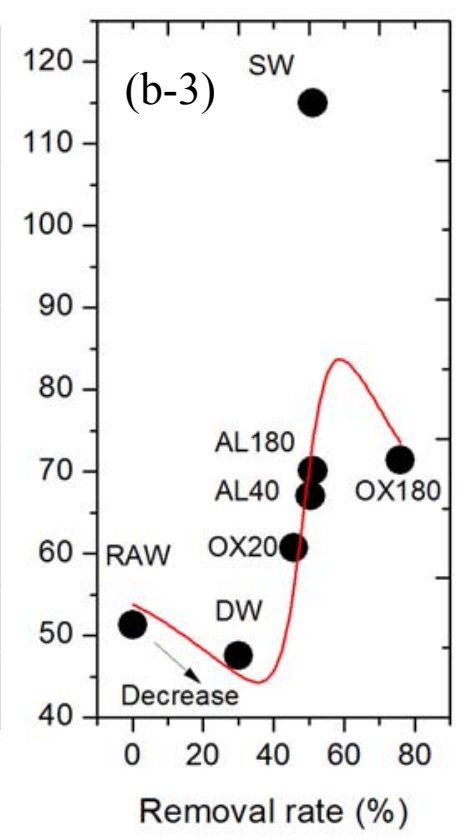

Figure 4 

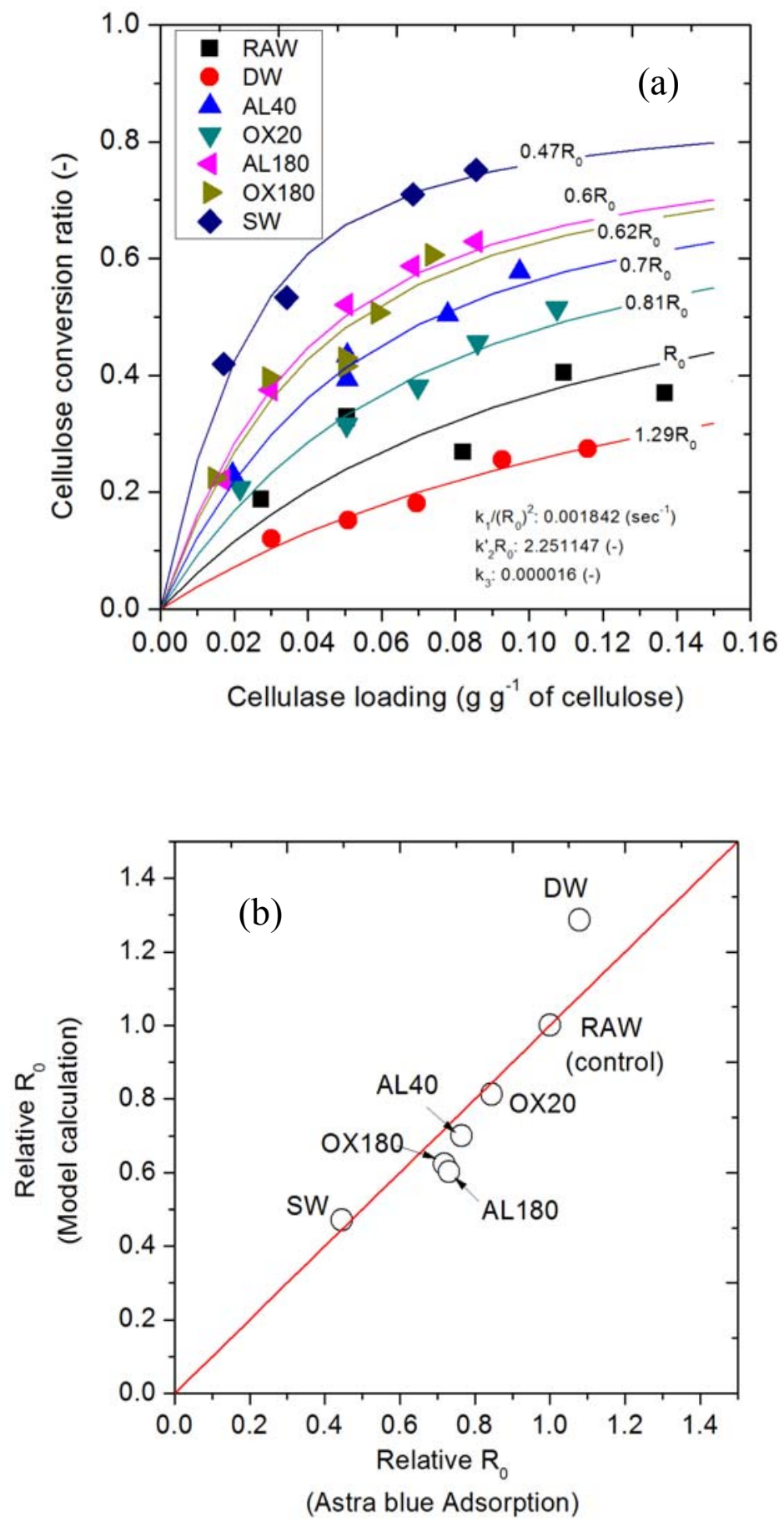

Figure 5 
(a)

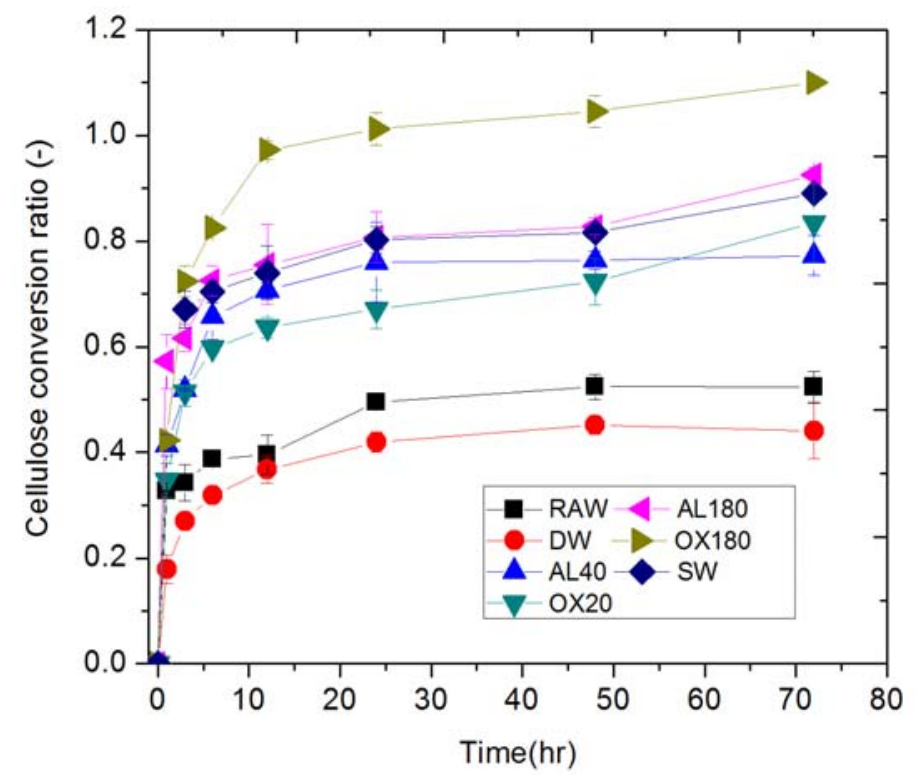

(b)
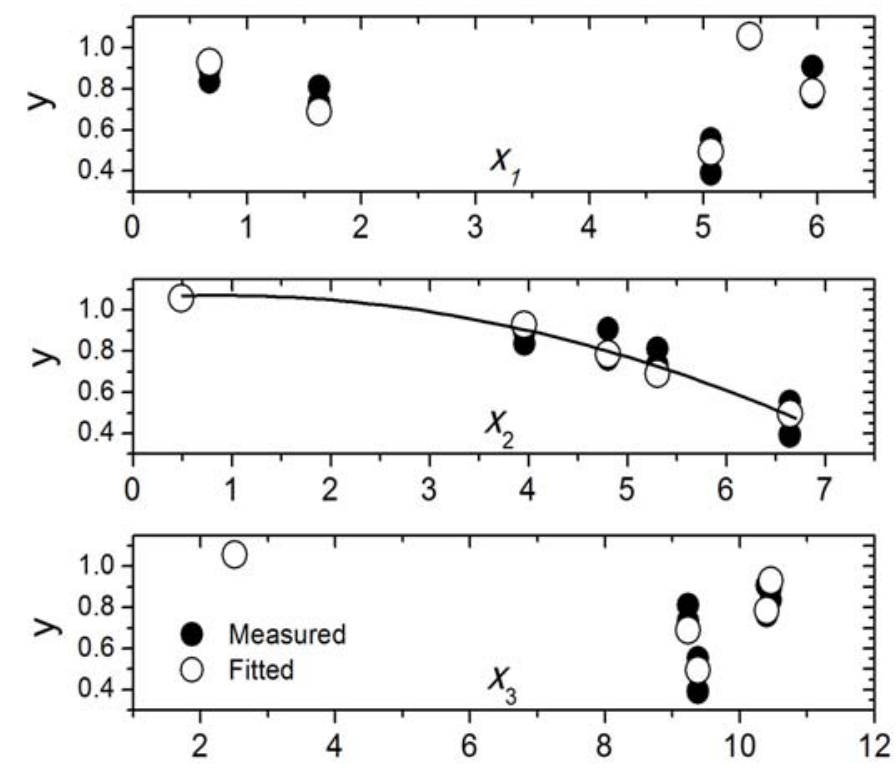

Figure 6 